\title{
Belphégor
}

\section{Philippe Druillet, avec la collaboration de David Alliot, Delirium : Autoportrait}

\section{Isabelle Antonutti}

\section{(2) OpenEdition}

1 Journals

\section{Electronic version}

URL: http://journals.openedition.org/belphegor/712

DOI: $10.4000 /$ belphegor.712

ISSN: 1499-7185

\section{Publisher}

LPCM

\section{Electronic reference}

Isabelle Antonutti, «Philippe Druillet, avec la collaboration de David Alliot, Delirium : Autoportrait », Belphégor [Online], 14 | 2016, Online since 16 July 2016, connection on 23 September 2020. URL: http://journals.openedition.org/belphegor/712 ; DOI : https://doi.org/10.4000/belphegor.712

This text was automatically generated on 23 September 2020.

\section{(c) (i) (9)}

Belphégor est mis à disposition selon les termes de la Licence Creative Commons Attribution - Pas d'Utilisation Commerciale - Pas de Modification 4.0 International. 
Philippe Druillet, avec la collaboration de David Alliot, Delirium : Autoportrait

Isabelle Antonutti

\section{REFERENCES}

Philippe Druillet, avec la collaboration de David Alliot, Delirium : Autoportrait, Paris, Les Arènes, 2014, 273 pp. 


\section{PHILIPPE ORUILLET \\ AVE DATI HHAT \\ DELIRIIUM}

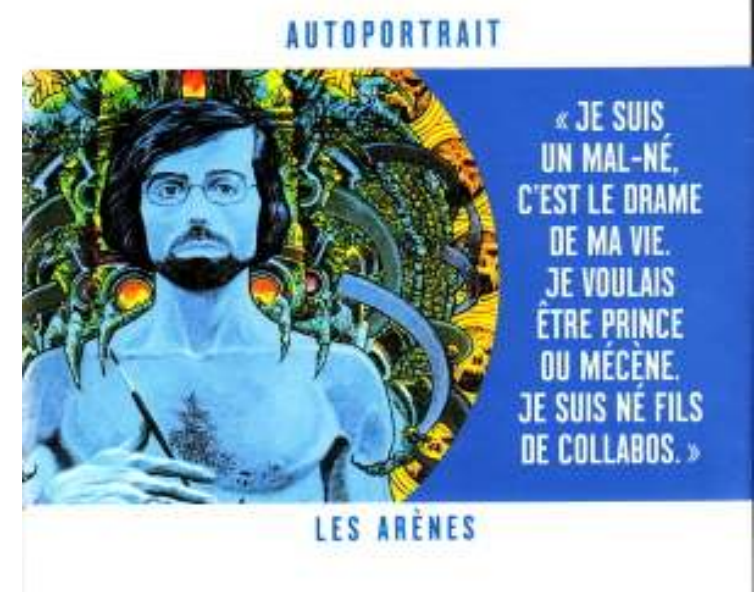

1 Philippe Druillet « le costaud qui l'ouvre tout le temps ${ }^{1}$ » se raconte, ou plutôt il égrène ses bons et mauvais souvenirs à la façon de flashbacks plus ou moins lumineux. L'autodestruction, la dépression, les excès, la violence heurtent d'emblée le lecteur. Les mémoires s'ouvrent sur les souvenirs d'une encombrante enfance dont il se serait bien passé, avec un père collaborationniste convaincu, qui s'enfuit à Sigmaringen à la Libération, et avec Céline comme premier médecin. Ces années ont généré une rage qui s'exprime par des affirmations telles que "je suis un cataclysme permanent ${ }^{2}$ », et une colère qui trouve un exutoire fabuleux dans la création. Quand, encore enfant, il se découvre une passion pour le dessin, sa vie commence à prendre sens. Le pouvoir créatif ne l'a cependant pas empêché de sombrer dans l'alcoolisme, ni de s'adonner à la drogue et n'a jamais réellement apaisé la colère qui l'habite. Le récit de sa vie est hanté par l'autodestruction.

2 Ses débuts dans la bande dessinée sont difficiles. Il commence à dessiner en 1969. Il vit avec Nicole, sa femme, et son ami Charles Cohen. Ce sont des années de vaches maigres. La vie amoureuse de Druillet a été semée de drames dont certains l'ont ravagé. Mais les femmes de sa vie ont toujours accompagné son travail. Grâce à son énorme capacité de travail et à sa volonté il force les portes des éditeurs. Il cachetonne de ci-delà, payé à la pièce. Pour vivre, il travaille aussi au Théâtre du Soleil. Cela aurait pu continuer longtemps ainsi, mais Ariane Mnouchkine l'oblige à choisir et elle le pousse vers le dessin : « Tu as un problème dans ta vie. Tu es entre deux choses (..) soit tu entres chez nous, soit tu dessines ${ }^{3}$ ». Alors, il choisit le dessin. Il se passionne pour la science-fiction et particulièrement pour Stefan Wul. Il dessine pour les magazines Fiction et Galaxie. Il rencontre Gérard Klein, Jacques Bergier, Jean-Claude Forest. Les premiers cachets confortables viennent du journal Pilote, où il savoure ses premiers vrais succès. Par la suite, il commence la publication d'albums chez Dargaud. Il en vendra plus de deux millions en quarante ans de carrière. Ses lecteurs sont de grands fans qui peuvent attendre des heures pour une dédicace. Son œuvre est intemporelle et à la première 
génération de lecteurs, aujourd'hui quinquagénaires, se sont ajoutés des admirateurs plus jeunes.

3 L'autoportrait présenté dans ce livre est intéressant à deux titres. Le premier intérêt est de suivre le parcours d'un dessinateur dans une période particulièrement riche pour la bande dessinée. Il décrit son passage du statut d'artisan à celui de peintre et artiste reconnu. Druillet est l'initiateur d'un style très personnel. Ses bandes dessinées s'exposent désormais dans les galeries d'art, ses œuvres ont été vendues aux enchères. Il a participé à de nombreuses aventures artistiques dans différents domaines, créant des décors d'opéra, de cinéma, du mobilier, des jeux vidéo. Pour s'amuser (ou arrondir ses fins de mois), il a aussi été restaurateur-faussaire pour un antiquaire en repeignant de vieilles toiles qu'il signait " Druillet, 1868 ». Bien sûr, dans la vie d'un dessinateur de bandes dessinées le festival d'Angoulême est un rendez-vous incontournable, il y participe dès la deuxième année. Le Grand prix est source d'inquiétude plus que d'attente. Enfin, en 1988, il lui est attribué. "Enfin, on va me foutre la paix!» s'exclame-t-il alors. Il est désormais membre de l'académie qui décerne le prix, ce qui lui donne l'occasion de regretter que les scénaristes, qu'il considère les clefs de l'album, soient oubliés dans cette cérémonie. Toute sa carrière est un combat pour sortir la bande dessinée de sa position de « distraction pour écervelés ${ }^{4}$ ».

4 Le deuxième intérêt de ces mémoires concerne les rencontres qui traversent le parcours de Druillet. On découvre Jean Boulet, dessinateur, critique de cinéma, illustrateur. Tous les portraits ne sont pas amicaux, et les critiques fusent: "Jacobs n'est pas doué pour les rapports humains ${ }^{5} »$. On ne sait toutefois jamais trop si ces jugements, sans appel, sont liés à un simple événement ou le fruit d'une plus longue expérience. Les relations avec le "gourou » Jodorowsky n'ont pas été simples, tout comme celles avec Moebius. «Morris, nous dit-il, est d'une radinerie peu croyable ${ }^{6}$ ». L'aventure Métal hurlant est peu et mal racontée dans cet ouvrage, mais elle a de toute façon été disséquée ailleurs. Druillet n'a plus envie d'en parler et il le clame sans grands états d'âme: "vous me faites tous chier avec Métal hurlant ${ }^{7}$ ». En quelques pages, il relate ses rapports avec Marcel Gotlib, Mandryka, Brétécher, L'Écho des savanes, et la faillite ultime de cette aventure. Les anecdotes sont expéditives, et les jugements tranchés, comme lorsqu'il qualifie Jean-Pierre Dionnet de « réacteur nucléaire » de ce magazine. La galerie de portraits qu'il offre est très bigarrée et ne se cantonne pas à la bande dessinée. Il travaille avec la cinéaste Josée Dayan, qu'il qualifie de «monstre de génie $^{8}$ ». Il considère Benjamin de Rothschild comme son mécène. Il lui a créé plus de trois cents meubles qui viennent décorer ses maisons et succursales bancaires. Il ose des comparaisons originales: "une vente aux enchères, c'est comme un orgasme collectif $^{9}{ }$. Il croise des hommes politiques et reste subjugué par François Mitterrand: " une force tellurique, un chêne de cinq mille ans, et la sagesse d'un druide ${ }^{10}$ ".

Philippe Druillet livre ses rencontres, des bribes de son histoire mais il raconte peu comment se construisent ses projets, les travaux qu'il mène ou auxquels il participe. Ses descriptions sont brèves et il assène nombre de jugements sans contexte. Il a du moins la lucidité de s'en excuser: «avec moi, ça part dans tous les sens ${ }^{11}$ ». La chronologie est fantasque et abrupte, au point qu'on s'y perd facilement. Il n'arrive que rarement qu'il s'approche d'une vision d'ensemble, et cela fait qu'on regrette de ne pas entrer plus en profondeur dans l'univers du peintre dessinateur et de partager si peu ses connaissances et son cheminement. Le délire de Druillet écrase tout, c'est la folie du personnage et c'est aussi la grande limite de ces mémoires. Les mises en perspectives 
sont rares: il y a les amis ou les ennemis, les faits et les actes. Le livre est issu d'entretiens menés par David Alliot, qui a enregistré leurs conversations et choisit de les restituer telles quelles. Le style est donc souvent fatigant, ce n'est ni du Audiard, ni du Frédéric Dard, l'écriture est lourde car rien n'est écrit et tout est dit. S'il y a la voix de Druillet, il manque l'image. On ne peut s'empêcher de se demander si un documentaire n'aurait pas mieux convenu à ces mémoires hurlantes.

\section{NOTES}

1. Philippe Druillet, David Alliot, Delirium : Autoportrait, Paris, Les Arènes, 2014, p.151.

2. Op.cit., p.267.

3. Op.cit., p.10.

4. Op.cit., p. 269.

5. Op.cit., p.165.

6. Op.cit., p. 151.

7. Op.cit., p.160.

8. Op.cit., p.266.

9. Op.cit., p.243.

10. Op.cit., p.215.

11. Op.cit., p.267. 